\title{
Tristramite, a new calcium uranium phosphate of the rhabdophane group
}

\author{
D. Atkin, I. R. Basham, and J. F. W. Bowles \\ Geochemistry and Petrology Division, Institute of Geological Sciences, 64 Gray's Inn Road, \\ London WC1X 8NG
}

\begin{abstract}
Tristramite, a new mineral of the rhabdophane group, has the composition $\left(\mathrm{Ca}_{0.54} \mathrm{U}_{0.29}^{4+} \mathrm{Fe}_{0.17}^{3+}\right)_{\Sigma 1.00}$ $\left[\left(\mathrm{PO}_{4}\right)_{0.79}\left(\mathrm{SO}_{4}\right)_{0.12}\left(\mathrm{CO}_{3}\right)_{0.07}\right]_{\Sigma 0.98} \cdot 1.77 \mathrm{H}_{2} \mathrm{O}$. It occurs as a late-stage replacement or matrix to brecciated uraninite (var. pitchblende) associated with sulphides in hydrothermal veins related to Hercynian granites in south-west England. It is hexagonal, space group $P 6_{2} 22$, with $a 6.913 \pm 0.003 \AA$ and $c 6.422 \pm 0.006 \AA$. The strongest lines of the indexed powder pattern are $2.99(100), 2.83$ (100), $2.14(50), 1.850(50), 5.99(40), 4.37(40), 3.46(30)$. For comparison, new indexed powder data for rhabdophane from Fowey Consols, Cornwall, are included. The mineral is pale yellow to greenish yellow, uniaxial positive with $\omega 1.644$ and $\varepsilon 1.664$, and does not fluoresce in either shortor long-wave ultraviolet light. The habit is acicular or fibrous and no cleavage has been observed. Density $\left(\mathrm{g} / \mathrm{cm}^{3}\right)$ 3.8-4.2 (meas.), 4.18 (calc.).
\end{abstract}

TRISTR A MITE was first discovered in the course of X-ray diffraction examination of radioactive material collected from south-west England by staff of the former Atomic Energy Division of the Geological Survey and Museum of Great Britain (now Institute of Geological Sciences). With the collection of additional material, and the advent of electron microprobe analysis, a full description of the mineral has now proved possible. Although tristramite has been identified in samples from dumps at several old copper and/or tin mines in Cornwall, including Trequeen, Wheal Alice, Wheal Buller, Wheal Damsel, and Wheal Providence, the best specimens found to date come from Wheal Trewavas. Here the mineral occurs both as a fine-grained aggregate and as coarser-grained infillings occupying fine fractures and cavities. The data that follow have been obtained from material from this occurrence, which is therefore considered to be the type locality. Specimens are lodged at the Geochemistry and Petrology Division of the Institute of Geological Sciences and at the British Museum (Natural History). The mineral is named after the medieval figure associated with the Arthurian legend. Both the name and descrip- tion of the mineral have been approved by the Commission on New Minerals and Mineral Names of the International Mineralogical Association.

Occurrence. Tristramite is found in uraninite (var. pitchblende)-bearing quartz veins in which commonly associated sulphides include chalcopyrite, pyrite, sphalerite, galena, and marcasite. At most of the localities studied, tristramite occurs as finegrained aggregates of acicular to fibrous crystals with an overall greenish body colour due to the intimate association with pitchblende. Direct replacement of vein pitchblende is sometimes found, as at Trequeen, but most commonly tristramite forms a matrix to brecciated pitchblende, often in close association with marcasite and chalcopyrite or digenite (fig. 1A and B). Secondary uranium minerals are also frequently present.

The dumps from which the type material for tristramite was obtained are sited on the coast of Cornwall at Trewavas Head (NGR SW597 267), the southernmost exposed area of the small Tregonning-Godolphin granite intrusion. Wheal Trewavas was active as a small copper producer about the middle of the last century (Dines, 1956) but pitchblende-bearing ore containing tristramite can still be collected from the old dumps. The locality is unique among those examined in that the common fine-grained matrix or replacive tristramite grades into coarser material in patches. More importantly, well-crystallized material occurs as an infilling to fine fractures or in cavities lined with chalcopyrite and marcasite (fig. 1C and D). The following description of the properties of tristramite has been made from this vein-type material, with the exception of density measurements, which were made on bulked samples of the replacement/matrix type.

Physical and optical properties. Tristramite has an acicular to fibrous habit. In the fine fractures and cavities crystals range in length from 5 to $80 \mu \mathrm{m}$ and have an estimated width in the range 2 to $5 \mu \mathrm{m}$. The width of the tristramite veinlets is 

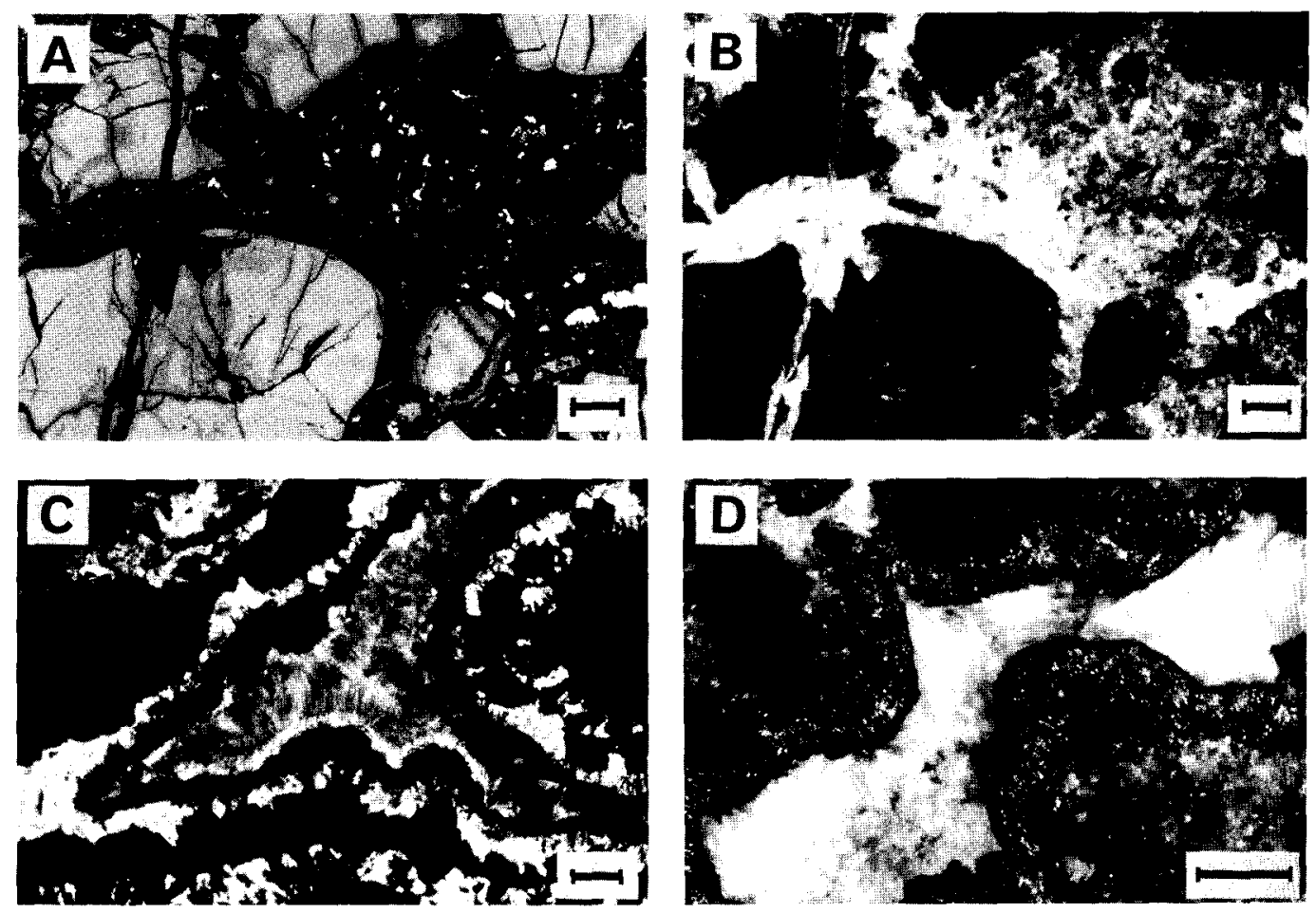

FIG. 1. Photomicrographs showing the mode of occurrence of tristramite in specimens from Trewavas Head: A (reflected light); brecciated pitchblende (light grey) oxidized along margins or bordering cracks (darker grey); matrix composed of fine-grained tristramite with scattered grains of pyrite. B as a but in transmitted light; lighter tones in the tristramite matrix correspond to areas of coarser grain size. c (transmitted light); well-crystallized tristramite as a cross-fibre infill to a cavity bordered by sulphides. D (reflected light, crossed polars); cavity with tristramite infill and surrounded by intergrowth of marcasite and pitchblende. Scale bar $=0.1 \mathrm{~mm}$.

generally less than $200 \mu \mathrm{m}$ and the crystals occur either in the form of a cross-fibre infill or as radial aggregates-a habit typical of rhabdophane. The colour is lustrous yellow to greenish yellow but colour banding is frequently shown due to variations in the content of ubiquitous minute blebs or plates of goethite, approximately $2 \mu \mathrm{m}$ across. The fine grain size of tristramite and the presence of intergrown goethite preclude any accurate density determinations although repeated separations were made by centrifuging in Clerici's solution in an attempt to remove impurities. On the basis of these experiments, the density was found to lie in the range $3.8-4.2 \mathrm{~g} / \mathrm{cm}^{3}$. The fibrous nature of the mineral did not permit any reliable hardness determinations and no cleavage could be confirmed.

In transmitted light the colour is very pale yellow to greenish yellow although the colour appears stronger when a polished block is observed under incident light. There is no fluorescence under either long or short-wave ultraviolet light. Tristramite is uniaxial positive with extinction parallel to the positive elongation or fibre-length. Refractive indices were determined as $\omega 1.644 \pm 0.002$ and $\varepsilon 1.664 \pm 0.002$. Pleochroism has not been observed but under crossed polars there is a tendency to show an anomalous blue birefringence colour.

Chemical composition. Electron microprobe analyses of the tristramite are given in Table $I$. The methods and the apatite and pyrite standards described by Bowles (1975) were used in conjunction with an artificially produced uranium-bearing glass (Smellie et al., 1978) and the quantitative correction programme of Mason et al. (1969). Qualitative analysis using an energy-dispersive system showed that only $\mathrm{Ca}, \mathrm{Fe}, \mathrm{U}, \mathrm{P}$, and $\mathrm{S}$ are present in concentrations over $0.1 \%$ within the range of elements from $\mathrm{Na}$ to $\mathrm{U}$, and no further elements were detected by optical spectroscopy.

Because of the fine grain size and textural relationships of the tristramite it was not possible to obtain pure material for separate determination of $\mathrm{H}_{2} \mathrm{O}$ content. However, partial wet chemical 
TRISTRAMITE, A NEW MINERAL

TABLE I. Electron-microprobe analysis of tristramite

$\left.\begin{array}{lrll}\hline & \multicolumn{2}{c}{2} & \\ \hline \mathrm{CaO} & 13.74 & \mathrm{Ca}^{2+} & 0.544 \\ \mathrm{UO}_{2}{ }^{*} & 35.08 & \mathrm{U}^{4+} & 0.289 \\ \mathrm{Fe}_{2} \mathrm{O}_{3} \dagger & 5.99 & \mathrm{Fe}^{3+} & 0.167\end{array}\right\} 1.00$

1. Weight per cent.

* Total U expressed as $\mathrm{UO}_{2}$.

$\dagger$ Total $\mathrm{Fe}$ expressed as $\mathrm{Fe}_{2} \mathrm{O}_{3}$.

$\ddagger \mathrm{CO}_{2}$ added to balance valency.

$\S \mathrm{H}_{2} \mathrm{O}$ added by difference.

2. Atomic proportions.

analysis of a concentrate, shown by X-ray powder photography to comprise only tristramite, chalcopyrite, goethite, and pitchblende, confirmed the $\mathrm{Ca}: \mathrm{P}$ ratio obtained by microprobe analysis. Apportioning the results of the wet chemical analysis so that $\mathrm{S}$ and $\mathrm{Fe}$ form chalcopyrite and $\mathrm{Fe}$ and $\mathrm{H}_{2} \mathrm{O}^{+}$form goethite leaves excess $\mathrm{H}_{2} \mathrm{O}$. When allocated to a tristramite content calculated on the basis of the $\mathrm{Ca}$ and $\mathrm{P}$ values, this indicates an $\mathrm{H}_{2} \mathrm{O}$ content in tristramite of the order of $15 \%$. An interpreted analysis is therefore made, by analogy with rhabdophane and brockite (Fisher and Meyrowitz, 1962), by first adding $\mathrm{CO}_{2}(2.46 \%)$ to achieve valency balance and then $\mathrm{H}_{2} \mathrm{O}(14.33 \%)$ to bring the total to $100 \%$. The presence of a small amount of $\mathrm{CO}_{2}$ was confirmed under the microscope from the observation of the evolution of gas bubbles when the mineral is immersed in $\mathrm{HCl}$ acid. The amount of $\mathrm{H}_{2} \mathrm{O}$ added is greater than found in rhabdophane but it is considered acceptable in view of the confirmatory evidence of the wet chemical data. Limited parallel heating experiments in the range 150 to $200^{\circ} \mathrm{C}$ also demonstrated approximately twice the weight loss from tristramite than from rhabdophane and suggested the water to be zeolitic in nature.

The formula calculated is therefore:

$\left(\mathrm{Ca}_{0.54} \mathrm{U}_{0.29}^{4+} \mathrm{Fe}_{0.17}^{3+}\right)_{\Sigma 1.00}$

$\left[\left(\mathrm{PO}_{4}\right)_{0.79}\left(\mathrm{SO}_{4}\right)_{0.12}\left(\mathrm{CO}_{3}\right)_{0.07}\right]_{\Sigma 0.98} \cdot 1.77 \mathrm{H}_{2} \mathrm{O}$

with the ideal formula

$\left(\mathrm{Ca}, \mathrm{U}^{4+}, \mathrm{Fe}^{3+}\right)\left[\left(\mathrm{PO}_{4}\right),\left(\mathrm{SO}_{4}\right),\left(\mathrm{CO}_{3}\right)\right] \cdot 1.5-2 \mathrm{H}_{2} \mathrm{O}$

where

$$
\mathrm{Ca}>\mathrm{U}^{4+}, \mathrm{Fe}^{3+} \text {, and } \mathrm{PO}_{4}>\mathrm{SO}_{4}, \mathrm{CO}_{3}
$$

TABLE II. $X$-ray powder data for tristramite and rhabdophane

\begin{tabular}{|c|c|c|c|c|c|c|c|}
\hline \multicolumn{4}{|c|}{ Tristramite } & \multicolumn{4}{|c|}{ Rhabdophane } \\
\hline hkil & $d_{\mathrm{calc}} \AA$ & $d_{\mathrm{obs}} \AA$ & $I$ & hkil & $d_{\text {calc }} \AA$ & $d_{\mathrm{obs}} \AA$ & $I$ \\
\hline 1010 & 5.99 & 5.99 & 40 & $10 \overline{10}$ & 6.03 & 6.03 & 55 \\
\hline $10\lceil 1$ & 4.38 & 4.37 & 40 & $10 \overline{1} 1$ & 4.38 & 4.38 & 55 \\
\hline 1120 & 3.46 & 3.46 & 30 & $11 \overline{2} 0$ & 3.48 & 3.48 & 50 \\
\hline $11 \overline{2} 1$ & 3.04 & 3.04 & 2 & $11 \overline{2} 1$ & 3.05 & 3.03 & 3 \\
\hline 2020 & 2.99 & 2.99 & 100 & $20 \overline{2} 0$ & 3.01 & 3.01 & 90 \\
\hline 1012 & 2.83 & 2.83 & 100 & $10 \overline{12}$ & 2.82 & 2.82 & 100 \\
\hline $20 \overline{21}$ & 2.71 & 2.70 & 1 & $20 \overline{2} 1$ & 2.72 & 2.73 & 1 \\
\hline 1122 & 2.35 & 2.35 & 25 & $11 \overline{2} 2$ & 2.35 & 2.35 & 20 \\
\hline $21 \overline{3} 0$ & 2.26 & 2.26 & 6 & $21 \overline{3} 0$ & 2.28 & 2.28 & 8 \\
\hline $20 \overline{2} 2$ & 2.19 & 2.19 & 2 & $20 \overline{2} 2$ & 2.19 & 2.19 & 4 \\
\hline 0003 & $2.14\}$ & 214 & 50 & $21 \overline{3} 1$ & 2.15 & 2.15 & 50 \\
\hline $21 \overline{3} 1$ & $2.13\}$ & 2.14 & 30 & 0003 & 2.12 & 2.13 & 10 \\
\hline 1013 & 2.02 & 2.01 & 4 & $30 \overline{30}$ & $2.01\}$ & & \\
\hline 3030 & 2.00 & 2.00 & 1 & $10 \overline{13}$ & $2.00\}$ & 2.01 & \\
\hline 3031 & 1.906 & 1.906 & 20 & $30 \overline{3} 1$ & 1.916 & 1.916 & 13 \\
\hline $21 \overline{3} 2$ & 1.850 & 1.850 & 50 & $21 \overline{3} 2$ & 1.853 & 1.853 & 50 \\
\hline 1123 & 1.820 & 1.821 & 3 & $11 \overline{2} 3$ & 1.813 & 1.815 & 5 \\
\hline $20 \overline{2} 3$ & 1.741 & 1.740 & 10 & $22 \overline{4} 0$ & $1.740\}$ & 1.740 & 20 \\
\hline $22 \overline{4} 0$ & 1.728 & 1.728 & 9 & $20 \overline{2} 3$ & $1.736\}$ & 1.140 & 20 \\
\hline $30 \overline{3} 2$ & 1.695 & 1.696 & 25 & 3032 & 1.699 & 1.699 & 20 \\
\hline $22 \overline{4} 1$ & 1.669 & - & - & 2241 & 1.678 & 1.681 & 1 \\
\hline 3140 & 1.660 & 1.662 & 11 & 3140 & 1.672 & 1.672 & 15 \\
\hline 3141 & 1.608 & 1.609 & 6 & 3141 & 1.617 & 1.619 & 5 \\
\hline $21 \frac{13}{3}$ & 1.555 & - & 一 & $21 \overline{3} 3$ & 1.553 & - & - \\
\hline 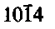 & 1.551 & 1.551 & 10 & $10 \overline{1} 4$ & 1.540 & 1.540 & 8 \\
\hline 2242 & 1.522 & 1.521 & 2 & 2242 & 1.527 & 1.527 & 2 \\
\hline 4040 & 1.497 & 1.497 & 3 & 4040 & 1.507 & 1.506 & 1 \\
\hline 3142 & 1.475 & 1.476 & 8 & 3142 & 1.480 & 1.481 & 6 \\
\hline 3053 & 1.460 & - & - & 4041 & 1.466 & 1.467 & 1 \\
\hline $40 \overline{4} 1$ & $1.458\}$ & 1456 & 8 & $30 \overline{3} 3$ & 1.460 & - & 一 \\
\hline 1124 & $1.456\}$ & 1.450 & 8 & 1124 & 1.448 & 1.448 & 6 \\
\hline 2024 & 1.415 & 一 & - & 2024 & 1.408 & - & - \\
\hline 3250 & 1.373 & - & - & 3250 & 1.383 & - & - \\
\hline 4072 & 1.357 & 1.356 & 4 & $40 \overline{42}$ & 1.362 & 1.361 & 3 \\
\hline 2243 & 1.345 & 1343 & 6 & 3251 & 1.351 & 1.352 & 4 \\
\hline 3251 & $1.343\}$ & $1.04 J$ & 0 & $22 \overline{4} 3$ & 1.346 & - & - \\
\hline $31 \overline{4} 3$ & 1.312 & - & - & 4150 & $1.315\}$ & 1315 & 5 \\
\hline 2134 & 1.309 & 1.309 & 20 & 3143 & $1.314\}$ & 1.313 & \\
\hline 4130 & 1.306 & - & - & $21 \overline{3} 4$ & 1.305 & 1.306 & 7 \\
\hline 4151 & 1.280 & 1.281 & 1 & 4151 & 1.288 & 1.288 & 1 \\
\hline 3252 & 1.263 & 1.263 & 9 & 3232 & 1.268 & 1.268 & 6 \\
\hline 1015 & 1.256 & - & - & $30 \overline{34}$ & $1.248\}$ & 1249 & 6 \\
\hline $30 \overline{34}$ & 1.251 & 1.251 & 7 & $10 \overline{15}$ & $1.247\}$ & & \\
\hline $40 \pi 3$ & 1.227 & - & - & $40 \overline{43}$ & 1.229 & - & - \\
\hline 4152 & 1.210 & 1.211 & 5 & 4152 & 1.216 & 1.216 & 3 \\
\hline 1125 & 1.204 & - & - & 5050 & 1.205 & - & - \\
\hline 5030 & 1.197 & - & - & $11 \overline{2} 5$ & 1.197 & - & - \\
\hline $20 \overline{25}$ & 1.180 & - & - & 5051 & 1.184 & 1.815 & 1 \\
\hline 5051 & $1.177\}$ & 1176 & 3 & 2244 & 1.175 & - & - \\
\hline 2244 & $1.176\}$ & $1.1 / 0$ & 3 & $20 \overline{25}$ & 1.174 & - & - \\
\hline 3253 & 1.156 & - & - & 3360 & $1.160\}$ & 1.160 & 3 \\
\hline 3144 & 1.154 & 1.152 & 7 & 3253 & $1.159\}$ & & \\
\hline 3360 & $1.152\}$ & 1.132 & 1 & 3144 & 1.153 & - & - \\
\hline 3361 & $1.134\}$ & 1.132 & 2 & $33 \overline{6} 1$ & $1.141\}$ & 1.139 & 1 \\
\hline $42 \overline{60}$ & $1.131\}$ & 1.132 & 2 & 4260 & $1.139\}$ & 1.139 & 1 \\
\hline 5052 & 1.122 & 1.122 & 1 & 5052 & 1.127 & 1.128 & 1 \\
\hline $21 \overline{3} 5$ & 1.117 & & & 4261 & 1.121 & 1.121 & 1 \\
\hline 4153 & 1.115 & 1.115 & 4 & 4153 & 1.118 & - & - \\
\hline 4261 & 1.114 & & & $21 \overline{3} 5$ & 1.112 & - & - \\
\hline 4074 & 1.095 & - & - & $40 \overline{4} 0$ & 1.095 & - & - \\
\hline 3362 & 1.084 & - & - & 3362 & 1.090 & 1.088 & 1 \\
\hline 3055 & 1.080 & - & - & 5160 & 1.083 & 1.082 & 2 \\
\hline 5160 & 1.075 & 1.075 & 4 & $30 \overline{35}$ & 1.076 & - & $\ldots$ \\
\hline 0006 & 1.070 & - & - & 4262 & 1.073 & 1.073 & 3 \\
\hline 4262 & 1.067 & 1.067 & 5 & $51 \overline{6} 1$ & 1.067 & - & - \\
\hline $51 \overline{6} 1$ & 1.061 & - & - & 0006 & 1.062 & - & - \\
\hline $10 \overline{16}$ & 1.054 & - & - & 5053 & 1.048 & - & - \\
\hline 5053 & 1.045 & & & $10 \overline{16}$ & $1.046\}$ & 1.044 & 3 \\
\hline 3254 & $1.044\}$ & 1.043 & 3 & 3254 & $1.044\}$ & 1.044 & 3 \\
\hline
\end{tabular}

The measurements were made on photographs taken in a $114.6 \mathrm{~mm}$ diameter camera with $\mathrm{Cu}-\mathrm{K} \alpha$ radiation $(\lambda=1.5418 \AA)$. 
$X$-ray data. X-ray diffraction data for tristramite were derived from $114.6 \mathrm{~mm}$ diameter DebyeScherrer powder cameras using $\mathrm{Cu}-K \alpha$ radiation and silicon as an internal standard. Intensities were visually estimated in conjunction with a calibrated intensity scale, the diffraction mount being prepared in the form of a sphere to avoid preferred orientation effects. Very minor amounts of goethite were associated with the tristramite, and reflections from this phase have been subtracted in the presentation of the tristramite data (Table II). The diffraction pattern of tristramite is analogous with that of rhabdophane and also brockite. For comparison, new powder data, derived under similar experimental procedures, for rhabdophane from the mine dumps of Fowey Consols, Cornwall (a $6.960 \pm 0.003 \AA, c 6.372 \pm 0.006 \AA$ ) are also listed in Table II. Systematic absences in the tristramite diffraction data are consistent with those of the space group $\mathrm{PG}_{2} 22$ determined for the hexagonal rare-earth phosphates (Mooney, 1950). Utilizing the method of least squares the cell dimensions of tristramite were determined as $a 6.913 \pm 0.003 \AA$, c $6.422 \pm 0.006 \AA, a: c=1: 0.929$ and $\bar{V} 265.8 \pm$ $0.5 \AA^{3}$. On the basis of three formula units in the unit cell and the atomic ratios derived in Table $I$ the calculated density is $4.18 \mathrm{~g} / \mathrm{cm}^{3}$. It is to be noted that samples of tristramite isolated from the replacement or matrix-type occurrences characteristically give multiphase $\mathrm{X}$-ray powder patterns and so are unsuitable for the derivation of satisfactory diffraction data.

Discussion. Several calcium uranium phosphate minerals have been described in addition to tristramite, including autunite, meta-autunite, phosphuranylite, phurcalite, ningyoite, and lermontovite. The status of lermontovite (Soboleva and Pudovkina, 1957) is uncertain, the mineral being inadequately described and lacking $\mathrm{X}$-ray diffraction data, but an incomplete chemical analysis showed a $\mathrm{U}: \mathrm{Ca}$ ratio of $10: 1$ ( $c f$. tristramite $\mathrm{U}: \mathrm{Ca}-1: 2$ ). Ningyoite is chemically similar to tristramite, with a powder diffraction pattern resembling that of rhabdophane, but it is pseudohexagonal and has been indexed on a primitive orthorhombic lattice (Muto et al., 1959). More recently, ningyoites have been described from the USSR (Belova et al., 1978) and Canada (Boyle et al., 1981). Both sets of authors derive cell parameters closely similar to those of the type material from the Ningyo-toge mine, Japan, but the diffraction data in both cases have been referred to a $C$-faced orthorhombic cell. The axial ratios $b: a$ from these three described ningyoites are 1.78 to 1.79 which contrast with the ratio 1.73 for the transformation to orthorhombic axes of a true hexagonal cell. Kucha (1979) has described unnamed monoclinic, hexagonal, and orthorhombic iron-thorium phosphates from Poland which are referred to the monazite, rhabdophane, and ningyoite groups of minerals respectively. Kucha notes a progressive increase in the water content from the monoclinic to the orthorhombic form.

The widespread occurrence of tristramite in south-west England indicates that late-stage phosphatization is an important part of the genetic sequence in the uranium-bearing hydrothermal vein mineralization. The process does not always result in the formation of tristramite, however, as some pitchblende is replaced by a phosphatebearing mineral with the coffinite structure. Preliminary chemical data on this mineral indicate that arsenic and possibly other cations can substitute for phosphorus and that the phosphatization process may be complex. A consideration of its paragenesis and that of tristramite in relation to late-stage phosphatization will be published at a later date.

Acknowledgements. The authors thank colleagues N. Cogger for wet chemical analysis and A. Milodowsky for Clerici separations. Dr M. H. Hey is also thanked for helpful comments. The paper is published with the approval of the Director, Institute of Geological Sciences (NERC).

\section{REFERENCES}

Belova, L. N., Gorshkov, A. I., and Ivanova, O. A. (1978) Dokl. Akad. Nauk SSSR, Earth Sci. Sect. 238, 132-4.

Bowles, J. F. W. (1975) Rep. Inst. Geol. Sci. No. 75/9.

Boyle, D. R., Littlejohn, A. L., Roberts, A. C., and Watson, D. M. (1981) Can. Mineral. 19, 325-31.

Dines, H. G. (1956) The metalliferous mining region of south-west England, 1, 240. Mem. Geol. Survey of Gt. Britain, London.

Fisher, F. G., and Meyrowitz, R. (1962) Am. Mineral. 47, 1346-55.

Kucha, H. (1979) Mineral. Polonica, 10, 3-25.

Mason, P. K., Frost, M. T., and Reed, S. J. B. (1969) B.M.-I.C.-N.P.L. computer programs for calculating corrections in quantitative $X$-ray microanalysis. Nat. Phys. Lab. (IMS), Rep. 2

Mooney, R. C. L. (1950) Acta Crystallogr. 3, 337-40.

Muto, T., Meyrowitz, R., Pommer, A. M., and Murano, T. (1959) Am. Mineral. 44, 633-50.

Smellie, J. A. T., Cogger, N., and Herrington, J. (1978) Chem. Geol. 22, 1-10.

Soboleva, M. V., and Pudovkina, I. A. (1957) [Uranium Minerals Handbook, Moscow pp. 181-2]; abstr. in Am Mineral. 43, 379-80, 1958.

[Manuscript received 10 October 1982] 